Ambiente \& Água - An Interdisciplinary Journal of Applied Science
ISSN 1980-993X - doi:10.4136/1980-993X
www.ambi-agua.net
E-mail: ambi.agua@gmail.com

\title{
Modelagem do regime térmico de um reservatório tropical de abastecimento público, Juiz de Fora, MG, Brasil
}

\author{
doi:10.4136/ambi-agua.1544
}

Received: 15 Oct. 2014; Accepted: 05 Nov. 2015

\author{
Flaviane de Fátima Cândida de Souza ${ }^{1 *}$; Celso Bandeira de Melo Ribeiro ${ }^{1}$; \\ Carlos Ruberto Fragoso Júnior ${ }^{2}$; Marcelo Henrique Otenio ${ }^{3}$ \\ ${ }^{1}$ Universidade Federal de Juiz de Fora (UFJF), Juiz de Fora, MG, Brasil \\ ${ }^{2}$ Universidade Federal de Alagoas (UFAL), Maceió, AL, Brasil \\ ${ }^{3}$ Empresa Brasileira de Pesquisa Agropecuária (EMBRAPA) Gado de Leite, Juiz de Fora, MG, Brasil \\ *Autor correspondente: e-mail: flavicandida@hotmail.com, \\ celso.bandeira@ufjf.edu.br, crubertofj@hotmail.com, \\ marcelo.otenio@embrapa.br
}

\section{RESUMO}

As alterações de temperatura da água e a dinâmica de estratificação térmica de um ecossistema aquático influenciam diretamente os processos físicos, químicos e biológicos. Devido às perturbações em que esses ambientes estão expostos, tais como mudanças climáticas e usos múltiplos da água, os estudos por meio de modelagem são importantes para suportar tomadas de decisão emergenciais e planejamentos futuros. Neste contexto, este trabalho teve como objetivo principal avaliar o comportamento térmico do reservatório de São Pedro utilizado para abastecimento de água, localizado no município de Juiz de Fora, MG, por meio da modelagem matemática com o modelo IPH-ECO para avaliar a temperatura superficial da água, com base em dados meteorológicos e hidrológicos, representando as forçantes e as condições de contorno, respectivamente. A modelagem do regime térmico mostrou correspondência significativa entre os valores simulados e observados, caracterizando o reservatório como um ambiente homogêneo. As simulações indicaram que a contribuição dos afluentes determina o padrão de distribuição espaço-temporal da temperatura da água no reservatório, limitando ou regularizando a sua variabilidade da temperatura.

Palavras-chave: hidrodinâmica, modelagem, temperatura da água.

\section{Thermal regime modeling of the public supply tropical reservoir at Juiz de Fora, MG, Brazil}

\begin{abstract}
Water temperature changes and the dynamics of thermal stratification of an aquatic ecosystem directly influence physical, chemical and biological processes. Due to disturbances in these environments, such as climate change and multiple water uses, studies which employ modeling are important to support emergency decision-making and future planning. In this context, this study evaluated the thermal behavior of the water supply reservoir of São Pedro, located in the city of Juiz de Fora, MG, using mathematical modeling with the IPH-ECO model to evaluate the surface temperature of water, based on meteorological and hydrological
\end{abstract}


data representing the forcing and boundary conditions, respectively. The modeling of the thermal system showed a significant correlation between predicted and observed values, characterizing the reservoir as a homogeneous environment. The simulations indicated that the tributary contribution determines the pattern of spatio-temporal distribution of water temperature in the reservoir, limiting or regulating the variability of its temperature.

Keywords: hydrodynamic, modeling, water temperature.

\section{INTRODUÇÃO}

A construção de reservatórios pode gerar impactos ambientais (i.e. eutrofização, sedimentação, toxicidade e veiculação de doenças), devido à transformação de um ambiente lótico em lêntico. Essas modificações nas condições de escoamento podem afetar, também, o regime térmico do sistema hídrico, além de introduzir novas condições químicas e biológicas (Ferreira e Cunha, 2013).

Os reservatórios são construídos em pontos estratégicos de uma bacia hidrográfica com o objetivo de atender diferentes demandas, tais como geração de energia, abastecimento, pesca, irrigação, recreação e aqüicultura (Christofolleti, 1980). Além destas também são muito utilizados para a regularização da vazão e amortecimento de cheias, apresentando-se como uma estrutura hidráulica de múltiplas finalidades para a sociedade.

No geral, a variação da temperatura de um corpo hídrico é ditada pelo regime climático natural e, associada à hidrodinâmica, afeta praticamente todos os fluxos ecológicos, como produção primária, nitrificação e respiração (Fragoso Jr. et al., 2009). Portanto, a avaliação da dinâmica do regime térmico auxilia na compreensão da variabilidade desses processos nos ambientes aquáticos.

Neste contexto, os modelos matemáticos se apresentam como ferramentas que ajudam na obtenção de uma visão dinâmica dos processos naturais, pois permitem a integração de dados dispersos espacialmente, com a possibilidade de prever diferentes situações ao simular cenários futuros (Rosman et al., 2001).

Conhecer a variação da temperatura de um corpo de água é particularmente importante por três motivos: (a) as descargas de efluentes em diferentes temperaturas podem causar efeitos negativos no ecossistema aquático; (b) a temperatura influencia as reações químicas e biológicas; e (c) a variação da temperatura afeta a densidade da água, e como consequência, altera os processos hidrodinâmicos e de transporte de massa (COPPE/UFRJ, 2007).

As condições de temperatura de um reservatório podem ser diferenciadas ao longo da coluna de água, por exemplo, promovendo um gradiente de densidade que forma uma barreira física que impede que compartimentos verticais se misturem (i.e. superfície e fundo). Essa barreira física cria zonas de circulação na coluna de água, amplificando o efeito da estratificação térmica. A ausência de variação térmica vertical, dentre outros fatores, facilita a homogeneização do corpo de água.

A compreensão do regime térmico em resposta ao clima e às condições hidrológicas é fundamental para o desenvolvimento de estratégias para gestão adaptativa da qualidade da água em reservatórios (Wang et al., 2012).

A modelagem do regime térmico de um reservatório depende do conhecimento das condições de contorno climáticas, que são as forçantes de temperatura do ar, radiação solar, evaporação, direção e intensidade do vento, precipitação e umidade, além dos dados hidrológicos que são as vazões de entrada e saída do reservatório.

Muitos e variados modelos de ecossistemas aquáticos foram desenvolvidos e publicados durante as últimas quatro décadas, com o objetivo de representar a variabilidade dos processos ecológicos. Dentre os modelos de qualidade da água utilizados em reservatórios 
podemos citar o IPH-ECO, desenvolvido no Instituto de Pesquisas Hidráulicas da Universidade Federal do Rio Grande do Sul, o SisBaHiA (Sistema Base de Hidrodinâmica Ambiental) desenvolvido na COPPE da Universidade Federal do Rio de Janeiro e o ELCOM (Estuary and Lake Computer Model) acoplado ao CAEDYM (Computacional Aquatic Ecosystem Dinamics Model) ambos desenvolvidos pelo CWR (Center of Water Research) da Universidade da Austrália.

No entanto, apesar de algumas tentativas terem sido feitas, trabalhos que tratam de abordagens integradas no espaço e no tempo em ecossistemas lacustres ainda são escassos (Mooij et al., 2010). Além disso, a complexidade de fatores envolvidos (i.e. poluição, usos múltiplos da água, espécies invasoras, alterações do uso e cobertura do solo na bacia) dificulta a análise e quantificação dos processos.

Assim, este trabalho tem como objetivo investigar o regime térmico do reservatório de São Pedro, localizado no município de Juiz de Fora (MG), por meio da modelagem hidrodinâmica, em duas dimensões na horizontal (2DH), com base nos dados meteorológicos e hidrológicos, utilizando o modelo ecológico desenvolvido no Instituto de Pesquisas Hidráulicas - IPH da Universidade Federal do Rio Grande do Sul, denominado IPH-ECO.

\section{MATERIAL E MÉTODOS}

\section{1. Área de estudo}

O Reservatório de São Pedro, também conhecido como Represa dos Ingleses ou Cruzeiro de Santo Antônio, localizada na Mesorregião da Zona da Mata Mineira/Microrregião de Juiz de Fora, está situada nas coordenadas $21^{\circ} 46^{\prime} 34,8^{\prime}$ ' $\mathrm{S} / 43^{\circ} 24^{\prime} 27,2$ '' $\mathrm{W}$, altitude média de $850 \mathrm{~m}$, possuindo $0,04 \mathrm{~km}^{2}$ de espelho de água próximo a mancha urbana do município de Juiz de Fora/MG, região oeste da cidade. Atualmente, consiste em um manancial urbano inserido em uma área apontada como vetor de crescimento pelo Plano Diretor do município (Juiz de Fora, 1999).

Criado em 1963, o reservatório teve início da sua operação somente em 1967, com o objetivo de abastecer parte da demanda do município. A produção de água da Estação de Tratamento de Água (ETA São Pedro), localizada no bairro São Pedro, é em média de $120{\mathrm{~L} . \mathrm{s}^{1}}^{1}$, variando de acordo com o nível do reservatório. Atualmente, este reservatório ainda constitui um importante manancial de abastecimento público, operado e mantido pela Companhia de Saneamento Municipal - CESAMA. Este manancial fica a $8 \mathrm{~km}$ da densa malha urbana e corresponde a 8\% do abastecimento da cidade (CESAMA, 2013).

Sob o clima Cwb (tropical de altitude) - clima mesotérmico com secas de inverno e chuvas concentradas de verão e verões brandos ou moderadamente quentes, na classificação de Koppen (Machado, 2010), a bacia hidrográfica do reservatório de São Pedro (BHRSP) ocupa uma área de 13,04 km² e seus principais afluentes são o Córrego São Pedro (margem esquerda) e o Córrego Grota do Pinto (margem direita). A bacia do córrego São Pedro tem seu exutório no rio Paraibuna que deságua na margem direita do rio Paraíba do Sul no município de Três Rios - RJ. A localização da bacia hidrográfica do reservatório de São Pedro na área urbana de Juiz de Fora é mostrada na Figura 1.

\subsection{O modelo IPH-ECO}

O modelo ecológico IPH-ECO é um sistema computacional desenvolvido no Instituto de Pesquisas Hidráulicas (IPH) da Universidade Federal do Rio Grande do Sul (UFRGS), voltado especialmente para o entendimento dos processos físicos, químicos e biológicos de corpos de água rasos e profundos, tais como lagos, reservatórios e estuários (Fragoso Jr., 2009). O modelo descreve as mais importantes interações hidrodinâmicas e abióticas, além dos principais processos bióticos, com a finalidade de auxiliar no entendimento de um 
determinado ecossistema aquático e está disponível para download em https://sites.google.com/site/iphecomodel/.

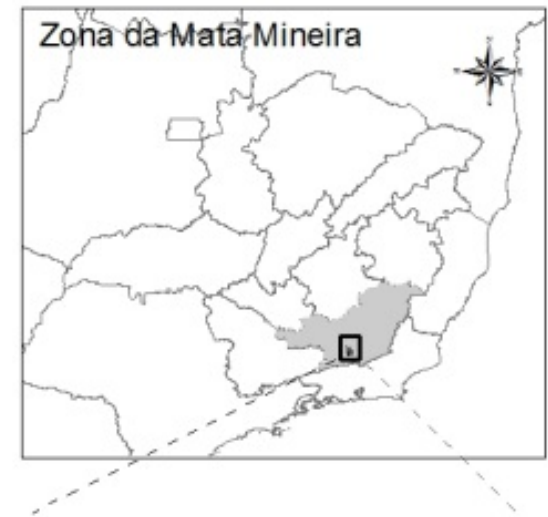

Área Urbana de Juiz de Fora
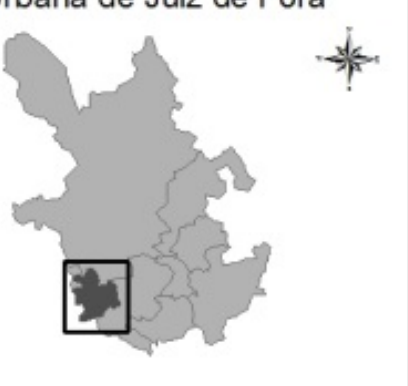

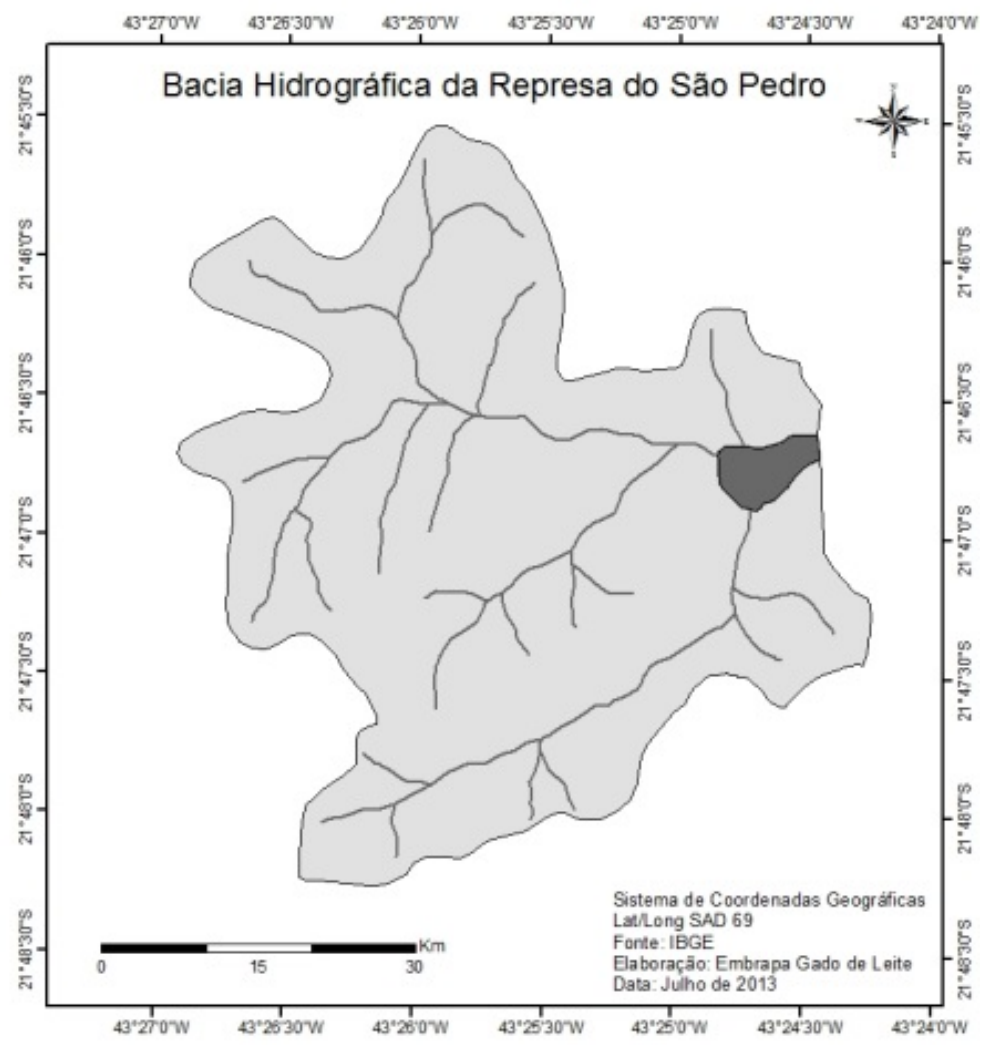

Figura 1: Localização da bacia afluente do reservatório de São Pedro.

Para este trabalho foi utilizado o módulo de balanço térmico associado ao módulo hidrodinâmico (bidimensional horizontal) do IPH-ECO para simulação da temperatura da água do reservatório de São Pedro. Uma vez que em corpos de água rasos, geralmente um modelo bidimensional na horizontal (2DH) é aconselhado, já que a dimensão horizontal predomina sobre vertical e nem sempre ocorre estratificação nestes sistemas (Rosman, 1999).

A escolha do IPH-ECO se baseou na possibilidade de representação do regime térmico para um reservatório raso e acesso à informações fundamentais para utilização do modelo por meio de curso específico, já que existem diversos modelos com variadas adequações e possibilidades de representação. Além disso, é preciso considerar o acesso a informações de forma documental ou até mesmo informal como base para utilização do modelo.

\subsection{Módulo hidrodinâmico}

As equações governantes para o módulo hidrodinâmico no IPH-ECO são derivadas das equações de Navier-Stokes para um escoamento turbulento sob a suposição de distribuição hidrostática de pressões. Estas equações são baseadas na conservação da massa e quantidade de movimento e podem ser escritas na forma diferencial (Equações 1, 2 e 3).

Equação da Continuidade:

$$
\frac{\partial \eta}{\partial t}+\frac{\partial[(h+\eta) u]}{\partial x}+\frac{\partial[(h+\eta) v]}{\partial y}=0
$$


Equação da Quantidade de Movimento:

$$
\begin{aligned}
& \frac{\partial u}{\partial t}+u \frac{\partial u}{\partial x}+v \frac{\partial u}{\partial y}=-g \frac{\partial \eta}{\partial x}-\gamma u+\tau_{x}+A_{h} \nabla^{2} u+f v \\
& \frac{\partial v}{\partial t}+u \frac{\partial v}{\partial x}+v \frac{\partial v}{\partial y}=-g \frac{\partial \eta}{\partial y}-\gamma+\tau_{y}+A_{h} \nabla^{2} v-f u
\end{aligned}
$$

em que:

t é o tempo;

u e v são as componentes da velocidade nas direções $\mathrm{x}$ e y no plano horizontal, respectivamente;

$\eta$ é elevação da superfície da água medida a partir de um nível de referência (Figura 2);

h é a profundidade medida a partir de um nível de referência;

g é a aceleração da gravidade;

f é o parâmetro de Coriolis; $\tau_{\mathrm{x}} \mathrm{e}$

$\tau_{\mathrm{y}}$ são as tensões do vento nas direções x e y, respectivamente;

$\nabla=\partial / \partial x \cdot \vec{i}+\partial / \partial x \cdot \vec{j}$ é um operador vetorial no plano $x-y ; e$

$\mathrm{A}_{\mathrm{h}}$ é o coeficiente de viscosidade turbulenta horizontal; e

$\gamma$ é coeficiente de atrito junto ao fundo.

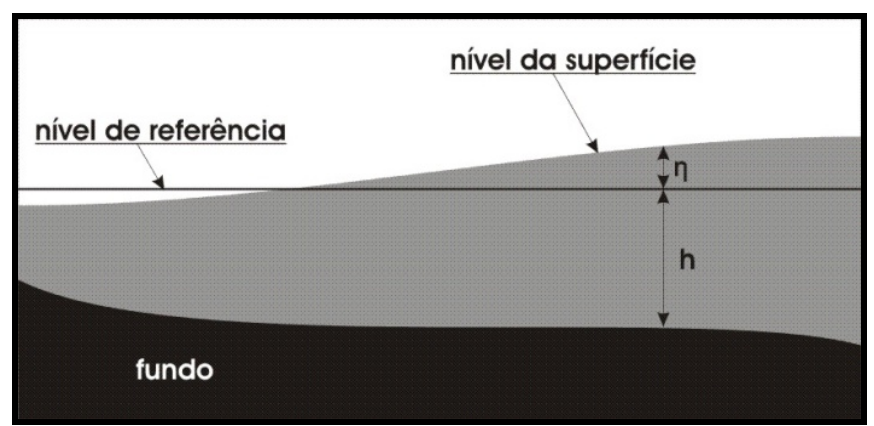

Figura 2. Elementos integrantes das equações de movimento.

O coeficiente de atrito junto ao fundo $(\gamma$ ) é estimado empiricamente (Equação 4).

$$
\gamma=\frac{g \sqrt{u^{2}+v^{2}}}{C_{z}^{2} H}
$$

em que:

$\mathrm{H}=\mathrm{h}+\eta$ é a profundidade total que corresponde à soma do nível de referência com $\mathrm{o}$ nível da superfície; e 
Cz é o coeficiente de atrito de Chèzy.

Como é comum em modelos de escoamentos, a tensão de atrito na superfície livre pelo vento é escrita em termos da velocidade do vento (Rosman, 1999; Equações 5 e 6).

$$
\begin{aligned}
& \tau_{x}=C_{D} \cdot W_{x} \cdot\|W\| \\
& \tau_{y}=C_{D} \cdot W_{y} \cdot\|W\|
\end{aligned}
$$

em que:

$C_{D}$ é o coeficiente de arraste do vento (valores utilizados 1 e -6);

Wx e Wy são as componentes do vetor velocidade do vento nas direções x e y em m.s ${ }^{-1}$, respectivamente, medidas a 10 metros da superfície livre e

$\|\mathrm{W}\|$ é o módulo do vetor velocidade do vento.

As equações de águas rasas (Equações de 1 a 3) não têm solução analítica genérica. Um esquema Euleriano-Lagragiano semi-implícito de diferenças finitas resolve numericamente as equações governantes para um número finito de pontos no espaço e no tempo (Casulli e Cheng, 1992). Este método necessita subdividir o domínio de aplicação em uma malha, comum número finito de células. As equações são discretizadas espacialmente em uma grade retangular que consiste em células computacionais quadradas com comprimento $\Delta \mathrm{x} e$ largura $\Delta y$.

\subsection{Balanço de calor}

No modelo IPH-ECO a temperatura da água é estimada a partir do balanço de calor entre a superfície da água e a atmosfera. Esse balanço é aplicação direta da primeira lei da termodinâmica para um fluido incompressível, a qual define que a variação da energia interna é igual à resultante dos fluxos de calor nos contornos do sistema. O balanço do fluxo de calor pode ser representado pela Equação 7.

$$
\Delta \mathrm{Q}=\mathrm{Q}_{\mathrm{RAOC}}^{\text {agua }}+\mathrm{Q}_{\mathrm{RAOL}}-\mathrm{Q}_{\mathrm{RWOL}}-\mathrm{Q}_{\mathrm{COND}}-\mathrm{Q}_{\mathrm{EVAP}} \pm \mathrm{Q}_{\mathrm{IN} / \mathrm{OUT}}
$$

em que:

$\mathrm{Q}_{\mathrm{RAOC}}^{\text {agua }}$ é o fluxo de calor referente à radiação atmosférica de onda curta,

$\mathrm{Q}_{\mathrm{RAOL}}$ é o fluxo de calor referente à radiação atmosférica de onda longa,

$\mathrm{Q}_{\mathrm{RwOL}}$ é o fluxo de calor referente à radiação da água de onda longa,

$\mathrm{Q}_{\mathrm{COND}}$ é o fluxo de calor referente à condução para a atmosfera,

$\mathrm{Q}_{\mathrm{EVAP}}$ é o fluxo de calor referente ao processo de evaporação e

$\mathrm{Q}_{\text {IN/OUT }}$ é o fluxo de calor resultante das entradas e saídas por advecção tais como escoamento superficial e subterrâneo, fluxo de afluentes, precipitação e fluxos de saída. $\mathrm{O}$ calor armazenado durante um intervalo de tempo pode ser convertido em temperatura (Equação 8). 


$$
S_{t}=\frac{\Delta Q}{\rho \cdot V \cdot c}
$$

em que:

V é o volume $\mathrm{em}^{3}$,

$\rho$ é a densidade da água em $\mathrm{kg} \mathrm{m}^{-3} \mathrm{e}$

$c$ é o calor específico da água em $\mathrm{J} \mathrm{kg}^{-1}{ }^{\circ} \mathrm{C}^{-1}$. A variabilidade temporal e espacial da temperatura da água pode ser avaliada para a equação de transporte de massa (Equação 9).

$$
\frac{\partial(H T)}{\partial t}+\frac{\partial(u H T)}{\partial x}+\frac{\partial(v H T)}{\partial y}=\frac{\partial}{\partial x}\left(K_{h} \frac{\partial(H T)}{\partial x}\right)+\frac{\partial}{\partial y}\left(K_{h} \frac{\partial(H T)}{\partial y}\right)+H \cdot S_{t}
$$

em que:

$K_{h}$ é o coeficiente de difusão horizontal $\mathrm{em} \mathrm{m}^{2} \cdot \mathrm{s}^{-1}$,

T é a temperatura da água em graus Celsious $\left({ }^{\circ} \mathrm{C}\right) \mathrm{e}$

$\mathrm{S}_{\mathrm{t}}$ é o termo de perdas e ganhos (dado pela Equação 8). Esta equação é resolvida numericamente por meio de um esquema explícito centrado de diferenças finitas.

\subsection{Amostragem e preparação dos dados para modelagem}

\subsubsection{Monitoramento da temperatura água}

A amostragem neste trabalho foi realizada a partir da seleção de três pontos representativos ao longo do espelho de água do reservatório, denominados Ponto 1, Ponto 2 e Ponto 3 (Figura 3).

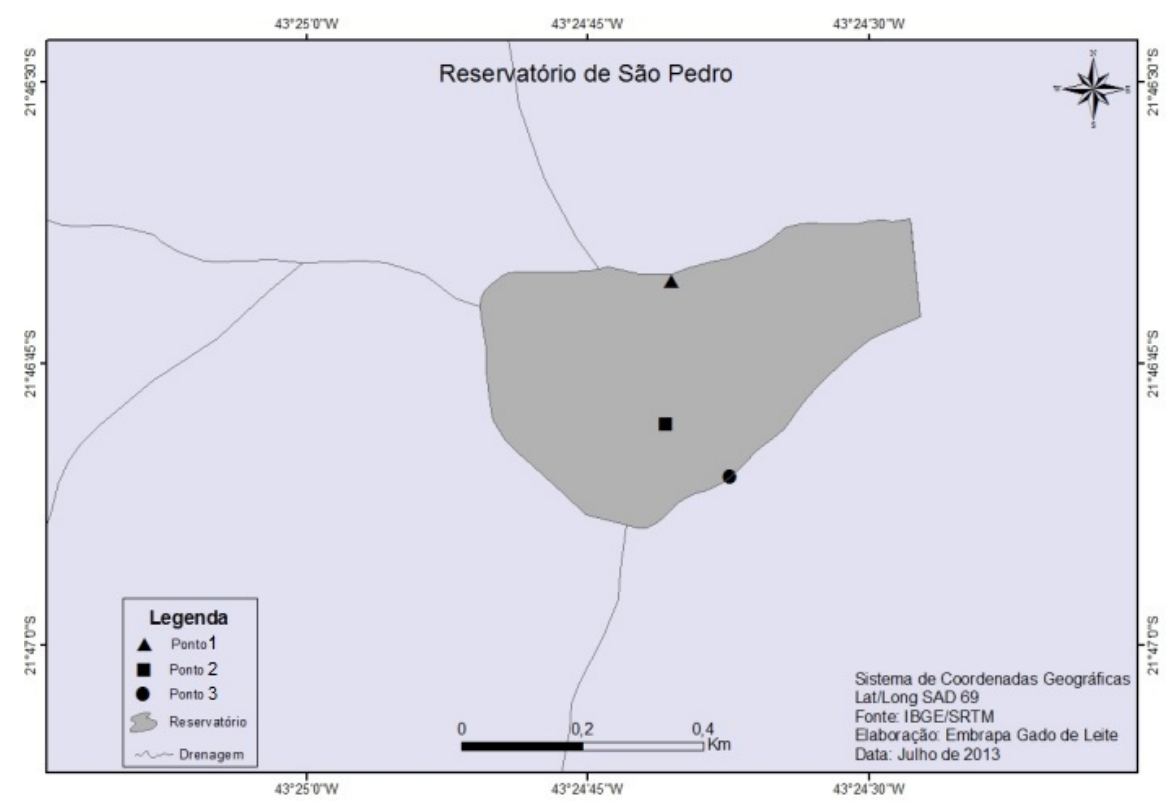

Figura 3: Distribuição dos pontos amostrais no reservatório de São Pedro.

A seleção de pontos para o monitoramento deste manancial foi uma etapa importante para se obter um referencial de qualidade do mesmo. Foram selecionados 3 pontos, dois pontos próximos às margens e um ponto na área central do reservatório. Foram realizadas 10 campanhas de amostragem, entre os meses de julho de 2010 a junho de 2011, 
intencionalmente com frequência mensal, porém nos meses de novembro de 2010 e março de 2011 não foi possível realizar campanhas devido às chuvas e dificuldades de deslocamento para acesso às áreas de coleta. As amostragens in situ foram realizadas com a utilização de uma sonda modelo HQ30d da Hach, com a finalidade de registrar a temperatura da água nos diferentes pontos selecionados no reservatório (Tabela 1).

Tabela 1. Valores de temperatura da água observados in situ.

\begin{tabular}{lccc}
\hline \multirow{2}{*}{ Meses } & \multicolumn{3}{c}{ Temperatura da água $\left({ }^{\circ} \mathrm{C}\right)$} \\
\cline { 2 - 4 } & Ponto 1 & Ponto 2 & Ponto 3 \\
\hline Julho/2010 & 19,08 & 19,23 & 19,16 \\
Agosto/2010 & 19,70 & 19,60 & 20,70 \\
Setembro/2010 & 22,70 & 23,00 & 23,40 \\
Outubro/2010 & 23,90 & 24,10 & 24,10 \\
Dezembro/2010 & 26,50 & 28,10 & 27,20 \\
Janeiro/2011 & 23,40 & 23,00 & 23,50 \\
Fevereiro/2011 & 27,00 & 27,20 & 27,20 \\
Abril/2011 & 22,20 & 21,90 & 22,10 \\
Maio/2011 & 18,80 & 19,10 & 18,70 \\
Junho/2011 & 18,90 & 18,70 & 18,90 \\
\hline
\end{tabular}

A temperatura da água foi monitorada próxima a superfície com cerca de 30 a $40 \mathrm{~cm}$ de profundidade controlado pela imersão do leitor da sonda utilizada na água. Estes dados foram comparados com os valores de temperatura estimados pelo IPH-ECO a partir dos dados climatológicos e dados das vazões de entrada e de saída do reservatório, os quais serão discutidos mais adiante.

Para a modelagem do regime térmico foi utilizado um intervalo de tempo de 10 segundos durante o período de simulação de 355 dias. Os principais dados de entrada do modelo são descritos a seguir.

\subsubsection{Dados meteorológicos}

Os dados meteorológicos foram fornecidos pela Estação Climatológica Principal situada na Universidade Federal de Juiz de Fora, operada e mantida pelo Instituto Nacional de Meteorologia na sede de Belo Horizonte/MG (INMET), são eles: temperatura do ar $\left({ }^{\circ} \mathrm{C}\right)$, evaporação $(\mathrm{mm})$, direção e intensidade do vento $\left(\mathrm{m}^{\mathrm{s}} \mathrm{s}^{-1}\right)$, precipitação $(\mathrm{mm})$ e umidade $(\%)$ com freqüência 00:00h/12:00h/18:00h. Os dados de radiação solar $\left(\mathrm{w} / \mathrm{m}^{2}\right)$ foram obtidos diretamente da Estação Climatológica Principal do INMET/MG com frequência de 1 hora, em sua página de internet. Esta estação dista cerca de $4,5 \mathrm{~km}$ do reservatório, o que garante pouca diferenciação das condições climáticas locais que poderiam afetar na comparação dos dados, como nebulosidade e precipitação.

\subsubsection{Levantamento batimétrico}

A batimetria do reservatório foi efetuada com a utilização de um Ecobatímetro (Garmin Fishfinder 140), aparelho que descreve a topografia do fundo do lago e os pontos foram marcados com um GPS (Garmin GPSMAP 76CSx) para garantir as amostragens nos mesmos pontos ao longo do monitoramento. Este levantamento foi realizado no dia 11 de julho de 2010, data referente ao primeiro monitoramento.

A batimetria revelou que a profundidade média do reservatório é de 2 metros (Figura 4), caracterizando-o como um reservatório raso, com predomínio da dimensão horizontal sobre a 
vertical, o que não justifica a aplicação de uma aproximação tridimensional. Desta forma, foi utilizada uma representação bidimensional na horizontal $(2 \mathrm{DH})$ do domínio. A discretização espacial consistiu em uma malha de $50 \times 50 \mathrm{~m}$ resultando em 450 células computacionais.

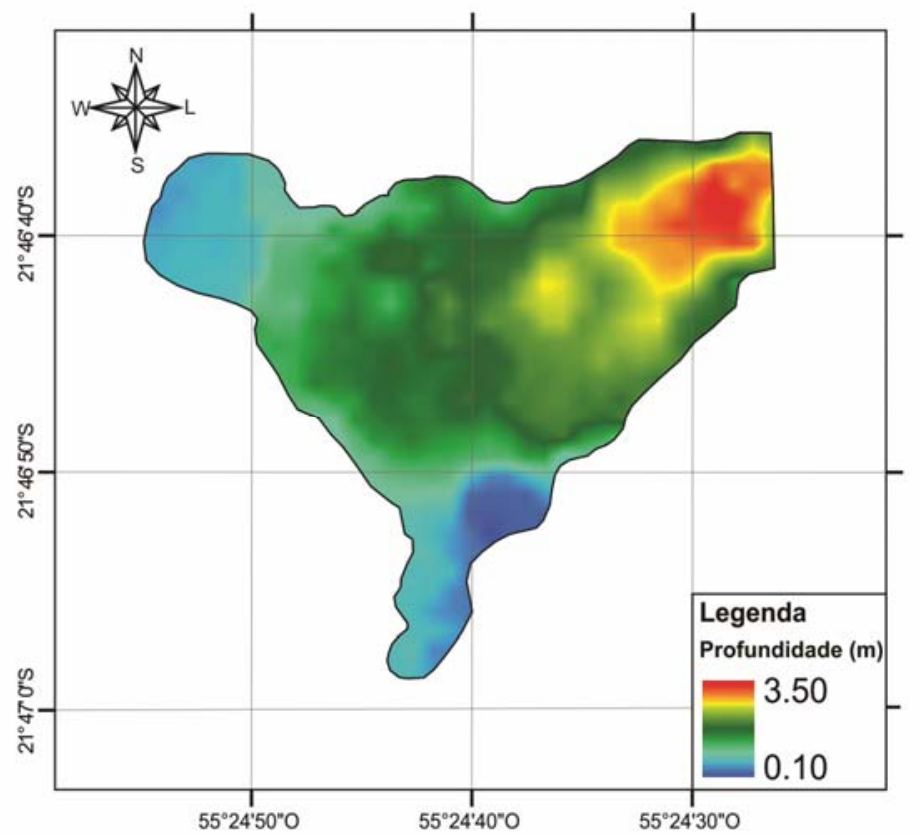

Figura 4: Batimetria do reservatório de São Pedro.

\subsubsection{Estimativa das vazões afluentes}

Uma estimativa das vazões de entrada do modelo foi obtida por meio do Método Racional Modificado (Euclydes, 1987) que resume todos os processos hidrológicos da bacia em um único coeficiente, o qual determina a parcela da chuva que se transforma em escoamento superficial (Equação 10).

$$
\mathrm{Q}=0,278 \cdot \mathrm{C} \cdot \mathrm{i} \cdot \mathrm{A} \cdot \varphi
$$

em que:

Q é a vazão na seção de interesse $\left(\mathrm{m}^{3} \mathrm{~s}^{-1}\right)$,

i a intensidade de chuva $\left(\mathrm{mm} \mathrm{h}^{-1}\right)$,

A é a área de drenagem na seção de interesse $\left(\mathrm{km}^{2}\right)$,

$\varphi$ o coeficiente de retardamento (adimensional), e

C é o coeficiente de escoamento superficial ou coeficiente de run off. Este valor é normalmente estimado em função do mapa de uso e ocupação do solo. Para bacia em estudo utilizou-se para os tipos de cobertura do solo os valores 0,20 para Mata, 0,80 para Área Urbana, 0,30 para Pasto/Solo Exposto e 0,0 para Água, conforme Tucci (2001).

O cálculo do coeficiente de retardamento é realizado com a Equação 11.

$$
\varphi=0,278-0,00034 . \mathrm{A}
$$

Para tanto é necessário o cálculo das áreas das bacias dos afluentes São Pedro e Grota do Pinto e seus respectivos coeficientes de retardamento.

O coeficiente de retardamento foi estimado com base em dados de vazão levantados 
in situ fazendo uso de um molinete hidrométrico nos afluentes São Pedro e Grota do Pinto. Os coeficientes de retardamento ajustados para os principais afluentes do reservatório foram: 0,2749944 para o São Pedro e 0,2768576 para o Grota do Pinto, cujas respectivas áreas de drenagem são $8,84 \mathrm{~km}^{2}$ e $3,36 \mathrm{~km}^{2}$.

A vazão de saída foi disponibilizada pela Estação de Tratamento de Água de São Pedro da Companhia de Saneamento Municipal - CESAMA que trata a água do reservatório de São Pedro e faz o controle horário dessa vazão para direcionar as operações dentro da estação.

\subsubsection{Saída do modelo}

Para a simulação da temperatura da massa de água do reservatório de São Pedro foram selecionados três pontos de saída do modelo (Pontos 1, 2 e 3), como mostra a Figura 5, com a finalidade de comparar os valores simulados com os valores observados em campo.

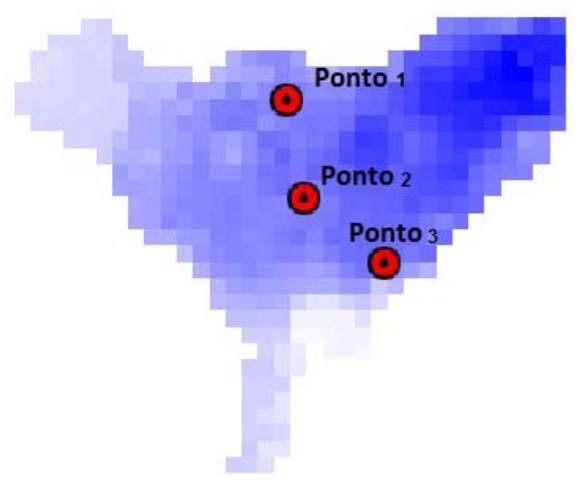

Figura 5: Pontos de saída selecionados no modelo IPH-ECO.

\subsubsection{Avaliação do desempenho do modelo}

O grau de correspondência entre a saída do modelo e os dados observados foi medido com a utilização de dois índices estatísticos: (a) a raiz do erro médio quadrático (REMQ), e (b) o coeficiente de Nash-Sutcliffe $\left(\mathrm{R}^{2}\right)$. $\mathrm{O}$ cálculo da raiz do erro quadrático médio e do coeficiente de determinação de Nash-Sutcliffe são apresentados nas Equações 12 e 13.

$$
\begin{aligned}
& \text { REMQ }=\sqrt{\frac{1}{N} \sum_{\mathrm{i}=1}^{\mathrm{N}}[\mathrm{Yobs}-\mathrm{Ycal}]^{2}} \\
& \mathrm{R}^{2}=1-\frac{\sum\left(\mathrm{Y}_{\mathrm{obs}}(\mathrm{t})-\mathrm{Y}_{\mathrm{cal}}(\mathrm{t})\right)^{2}}{\sum\left(\mathrm{Y}_{\mathrm{obs}}(\mathrm{t})-\overline{\mathrm{Y}}_{\mathrm{obs}}(\mathrm{t})\right)^{2}}
\end{aligned}
$$

em que:

REMQ é raiz do erro médio quadrático,

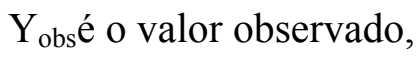

$\mathrm{Y}_{\text {cal }}$ é o valor estimado ou calculado pelo modelo,

$\mathrm{N}$ é o número total de valores,

$\mathrm{R}^{2}$ é o coeficiente de Nash-Sutcliffe e

$\bar{Y}_{\text {obs }}$ é a média dos valores observados. 


\section{RESULTADOS E DISCUSSÃO}

\subsection{Simulações da temperatura da água}

Ao final da simulação, o modelo IPH-ECO estimou a temperatura da água para os pontos de interesse em um período total de 355 dias, iniciando às 00:00 horas do dia 01/07/2010 e finalizando às 23:00 horas do dia 01/06/2011. Esse período de simulação corresponde ao período de monitoramento realizado no reservatório permitindo observar o comportamento térmico nos períodos seco e chuvoso ao longo do ano em questão. A comparação entre as temperaturas da água simuladas e observadas entre os meses de julho de 2010 a junho de 2011 nos pontos 1, 2 e 3 é mostrada, respectivamente, na Figura 6.
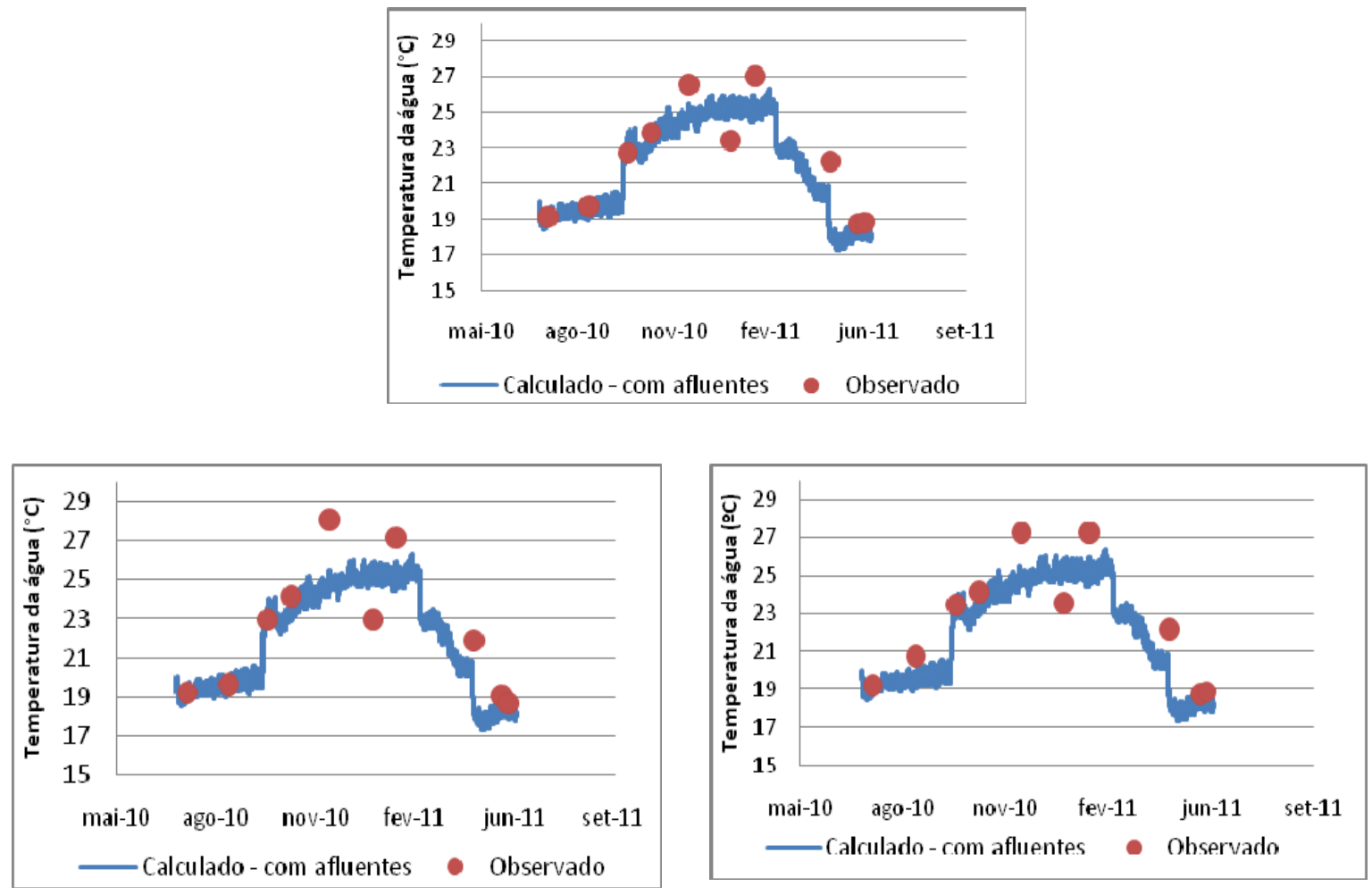

Figura 6. Variação da temperatura da água de Julho de 2010 a Junho de 2011. a) Comparação entre os valores de temperatura da água simulados (linha contínua) e observados (pontos) no Ponto 1 (área central do reservatório). b) Comparação entre os valores de temperatura da água simulados (linha contínua) e observados (pontos) no Ponto 2 (margem esquerda do reservatório). c) Comparação entre os valores de temperatura da água simulados (linha contínua) e observados (pontos) no Ponto 3 (margem direita do reservatório).

Ao se analisar a Figura 6 pode-se perceber que os valores simulados e observados apresentam boa correspondência ao longo do tempo. Os indicadores da eficiência do ajuste apresentaram bons valores ( $\mathrm{REMQ}<2 \%$ e $\left.\mathrm{R}^{2}>0,75\right)$ no período de simulação, caracterizando um grau de correspondência significativo para a modelagem da temperatura da água nos pontos de saída selecionados no IPH-ECO. Os dados observados e calculados apresentam correspondência direta com o clima tropical de altitude com temperaturas mais elevadas no período chuvoso (novembro a março) e mais brandas no período seco (abril a outubro).

Praticamente toda energia que controla o metabolismo de um reservatório advém da energia solar. Ferreira e Cunha (2013), ao desenvolver e aplicar um modelo unidimensional para simular o comportamento térmico do reservatório do Rio Verde, localizado na Região Metropolitana de Curitiba - PR, observaram que a formação estratigráfica no reservatório 
depende principalmente da incidência de radiação solar e que os ventos não seriam eficientes em misturar a coluna de água. Porém, para o reservatório de São Pedro, os dados de campo e simulações do comportamento térmico revelam proximidade dos valores de temperatura verificados nos três pontos amostrais caracterizando o reservatório como um ambiente homogêneo (Tabela 2).

Tabela 2. Cálculo da Raiz do Erro Médio Quadrático (REMQ) e coeficiente de determinação $\mathrm{R}^{2}$.

\begin{tabular}{|c|c|c|c|c|c|c|c|c|c|}
\hline & \multicolumn{6}{|c|}{ Temperatura $\left({ }^{\circ} \mathrm{C}\right)$} & \multirow{2}{*}{\multicolumn{3}{|c|}{ Cálculo dos índices por ponto }} \\
\hline & \multicolumn{3}{|c|}{ Valores Observados } & \multicolumn{3}{|c|}{ Valores Estimados } & & & \\
\hline & Ponto 1 & Ponto 2 & Ponto 3 & Ponto 1 & Ponto 2 & Ponto 3 & Ponto 1 & Ponto 2 & Ponto 3 \\
\hline Julho/2010 & 19,23 & 19,08 & 19,16 & 20,00 & 20,00 & 20,00 & 0,5928 & 0,8462 & 0,7055 \\
\hline Agosto/2010 & 19,6 & 19,7 & 20,7 & 19,47 & 19,50 & 19,44 & 0,0166 & 0,0387 & 1,5817 \\
\hline Setembro/2010 & 23,0 & 22,7 & 23,4 & 19,72 & 19,76 & 19,67 & 10,7662 & 8,6201 & 13,8823 \\
\hline Outubro/2010 & 24,1 & 23,9 & 24,1 & 23,44 & 23,45 & 23,44 & 0,4354 & 0,2049 & 0,4309 \\
\hline Dezembro/2010 & 28,1 & 26,5 & 27,2 & 24,67 & 24,65 & 24,70 & 11,7346 & 3,4109 & 6,2275 \\
\hline Janeiro/2011 & 23,0 & 23,4 & 23,5 & 25,06 & 25,07 & 25,06 & 4,2556 & 2,7805 & 2,4358 \\
\hline Fevereiro/2011 & 27,2 & 27,0 & 27,2 & 25,33 & 25,32 & 25,35 & 3,4848 & 2,8099 & 3,4048 \\
\hline Abril/2011 & 21,9 & 22,2 & 22,1 & 21,48 & 21,46 & 21,50 & 0,1791 & 0,5420 & 0,3616 \\
\hline Maio/2011 & 19,1 & 18,8 & 18,7 & 17,84 & 17,82 & 17,88 & 1,5806 & 0,9533 & 0,6792 \\
\hline Junho/2011 & 18,7 & 18,9 & 18,9 & 18,13 & 18,13 & 18,15 & 0,3203 & 0,5968 & 0,5677 \\
\hline REMQ & & & & & & & 1,83 & 1,44 & 1,74 \\
\hline $\mathbf{R}^{2}$ & & & & & & & 0,75 & 0,81 & 0,77 \\
\hline
\end{tabular}

\subsection{Representatividade do efeito dos afluentes no regime térmico do reservatório}

Com a finalidade de avaliar a influência das vazões afluentes no regime térmico do reservatório de São Pedro, foi realizada uma nova simulação retirando as vazões de entrada e saída. Os resultados desta simulação foram comparados com os dados observados e com a simulação original, considerando as vazões de entrada e saída (Figura 7).

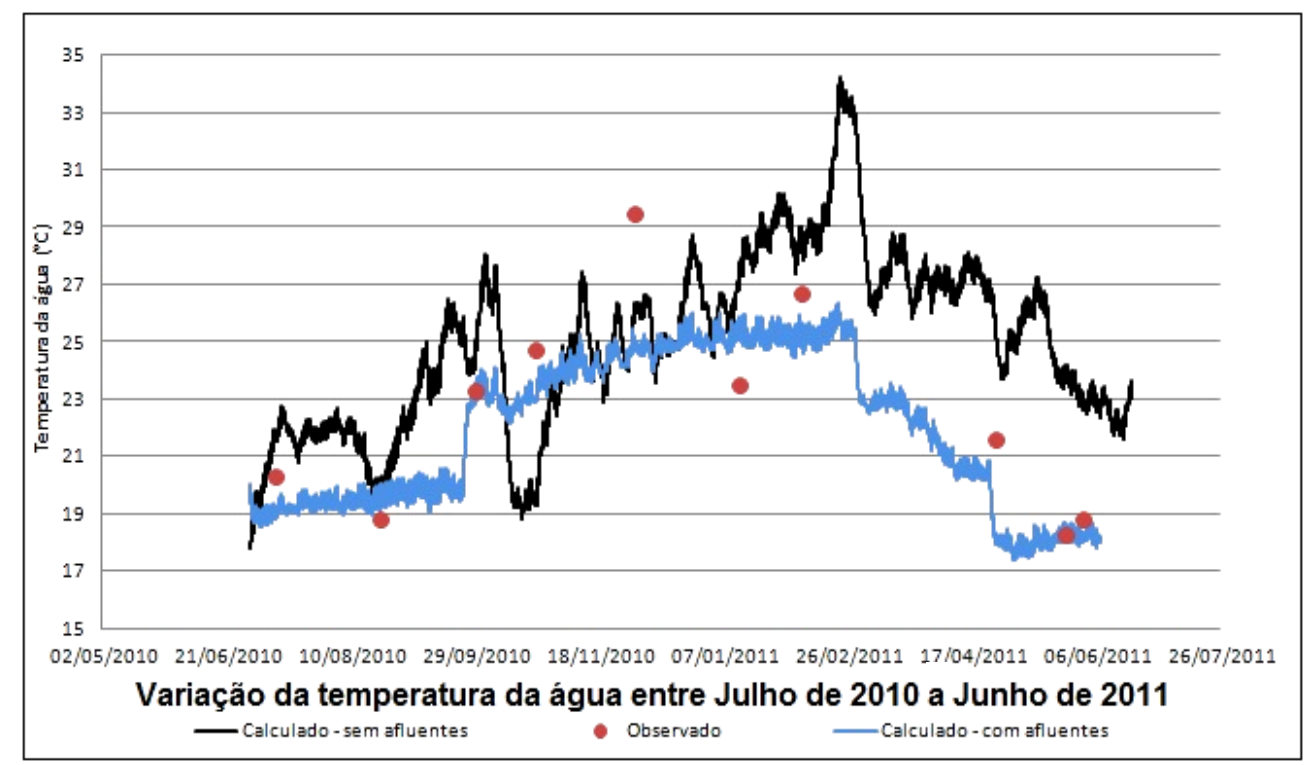

Figura 7. Variação da temperatura do reservatório com e sem os afluentes (Ponto 2). 
Nesta circunstância, mostra-se a influência dos afluentes no regime térmico do reservatório, pois a proximidade dos valores observados com os valores calculados mostrou-se relacionada ao fato de se considerar as vazões dos afluentes, ou seja, os afluentes Grota do Pinto e São Pedro controlam a temperatura do reservatório de São Pedro. Fato este também pode ser justificado por conta do tamanho do reservatório e as vazões dos afluentes, onde a mistura e distribuição das temperaturas das águas ocorrem de forma rápida, respeitando a sazonalidade imposta pelo clima tropical de altitude. As alterações climáticas influenciam sobremaneira a dinâmica de temperatura dos afluentes e consequentemente o reservatório.

Destarte, Fantin-Cruz et al. (2010) apontam que o regime térmico dos rios pode ser afetado por outras perturbações provocadas por ações humanas, como efluentes térmicos, redução no fluxo dos rios (irrigação, hidrelétricas) e lançamentos de águas a partir de barragens a montante dos rios. Os lançamentos que atingem os afluentes e o reservatório de São Pedro são basicamente representados por esgotos domésticos e não há barragens a montante. Eles apontam ainda que se devem considerar inclusive alterações na temperatura da água à jusante do reservatório, que são influenciadas por condições ligadas a variáveis operacionais (volume, descarga), limnológicas (tempo de retenção, padrão de estratificação e gradientes térmicos), além da posição da barragem ao longo do perfil longitudinal do rio.

O fluxo dos rios é capaz de influenciar na produtividade biológica de um corpo hídrico, interferindo em processos como eutrofização, ciclagem de nutrientes e atividades fotossintéticas. Para Collischonn e Motta Marques (2003), de um modo geral os rios trazem maior parte dos nutrientes e sedimentos para o interior dos lagos e reservatórios, por isso, a circulação originada pelas entradas desses afluentes é particularmente importante.

Os resultados apresentados por Pacheco et al. (2014), ao investigar o Reservatório do Funil, localizado no município de Resende - RJ, mostram que a variabilidade espacial da concentração de clorofila $(\mathrm{Chl})$ e $\mathrm{CO}_{2}$ está mais relacionada a mudanças no fluxo do rio ao longo do ano do que fatores ambientais, tais como temperatura do ar e radiação solar. Nesse sentido, quando o fluxo do rio atuar como regulador da temperatura de um reservatório, também será capaz de condicionar processos físicos, químicos e biológicos, visto que a temperatura é um fator físico que interfere diretamente na estrutura das comunidades biológicas e processos ecossistêmicos.

A variabilidade das vazões se apresentou conforme esperado para o contexto climatológico, com volumes maiores no período chuvoso e menores no período seco. A maior vazão ocorreu no mês de janeiro de $2011\left(0,2294 \mathrm{~m}^{3} / \mathrm{s}\right)$ no córrego São Pedro, cuja bacia possui a maior área de contribuição.

\section{CONCLUSÃO}

Foi possível representar o regime térmico do reservatório de São Pedro por meio da modelagem hidrodinâmica $2 \mathrm{DH}$, com base em dados meteorológicos e hidrológicos, utilizando o modelo IPH-ECO. O contexto climatológico como principal fator influenciador das condições térmicas da água a partir das trocas de calor da atmosfera com a superfície de água foi fundamental para realização deste trabalho, visto que os resultados das simulações mostraram valores de temperatura em consonância direta com as condições do clima tropical de altitude.

Nossos resultados mostraram temperaturas simuladas, em média $22^{\circ} \mathrm{C}$, próximas às temperaturas observadas, em média $22,21^{\circ} \mathrm{C}$. A simulação satisfatória do regime térmico é essencial para investigar os processos ecossistêmicos, uma vez que a temperatura é um fator que influencia diretamente nesses processos. Essa representatividade significativa no modelo suportaria testar cenários com mudanças de temperatura e garantir ações previamente necessárias para prevenir eventuais efeitos negativos à diversidade biológica, além da 
operação e manutenção do sistema de abastecimento.

A contribuição dos afluentes se mostrou muito importante para as simulações hidrodinâmicas, pois a variação das vazões limita ou regulariza as temperaturas do reservatório de São Pedro. Por se tratar de um reservatório pequeno e raso, as temperaturas são mais limitadas às vazões dos afluentes caracterizando, assim, uma baixa capacidade deste reservatório de regularização de suas temperaturas.

\section{AGRADECIMENTOS}

Os autores agradecem ao Programa de Pós-Graduação em Ecologia da Universidade Federal de Juiz de Fora (PGECOL), ao Departamento de Engenharia Sanitária e Ambiental da Universidade Federal de Juiz de Fora, à Embrapa Gado de Leite (CNPq), à Coordenação de Aperfeiçoamento de Pessoal de Nível Superior (CAPES) e ao Corpo de Bombeiros de Juiz de Fora pelo apoio ao trabalho. Os autores agradecem ao CNPq, Processo número 473854/20082 e à Embrapa código Infoseg 06.08.06.002.00.00 pelo apoio financeiro ao trabalho.

\section{REFERÊNCIAS}

CASULLI, V.; CHENG, R. Semi-implicit finite difference methods for three-dimensional shallow water flow. International Journal for Numerical Methods in Fluids, v. 15, p. 629-648, 1992. http://dx.doi.org/10.1002/fld.1650150602

COMPANHIA DE SANEAMENTO MUNICIPAL DE JUIZ DE FORA - CESAMA. Website. Disponível em: www.cesama.br. Acesso: em abr. 2013.

CHRISTOFOLLETI, A. Geomorfologia. São Paulo: Blucher, 1980.

COLISCHONN, W.; MOTTA MARQUES, D. L. Desenvolvimento de modelo bidimensional de transporte de sedimentos e nutrientes para lagos. In: CONGRESSO BRASILEIRO DE LIMNOLOGIA, 9., 2003, Juiz de Fora. Anais... Juiz de Fora: ICB; UFJF - MG, (2003).

EUCLYDES, H. P. Saneamento agrícola: atenuação de cheias: metodologia e projeto. Belo Horizonte: Rural Minas, 1987.

FANTIN-CRUZ, I.; TONDATO, K. K.; MARQUES, D. M.; PEDROLlO, O. Regime térmico em águas correntes e sua importância na estrutura do habitat e na biologia de organismos aquáticos. Revista Caminhos de Geografia, v. 11, n. 36, p. 295-307, 2010.

FERREIRA, D. M.; CUNHA, C. Simulação numérica do comportamento térmico do reservatório do Rio Verde. Revista Engenharia Sanitária e Ambiental, v. 18, n. 1, jan./mar. 2013.

FRAGOSO JR., C. R.; FERREIRA, T. F.; MOTTA MARQUES, D. M. L. Modelagem ecológica em ecossistemas aquáticos. 1. ed. São Paulo: Oficina de Textos, 2009. v. 1. $304 \mathrm{p}$.

FRAGOSO JR., C. R. Modelagem tridimensional da estrutura trófica em ecossistemas aquáticos continentais. 2009. Tese (Doutorado em Recursos Hídricos e Saneamento Ambiental) - Instituto de Pesquisas Hidráulicas, Universidade Federal do Rio Grande do Sul, Porto Alegre, 2009. 
INSTITUTO ALBERTO LUIZ COIMBRA DE PÓS-GRADUAÇÃO E PESQUISA DE ENGENHARIA - COPPE/UFRJ. Manual do Usuário do SisBaHia. 2007. Disponível em: http://www.sisbahia.coppe.ufrj.br/Arquivos_Gerais. Acesso em: jul. 2013.

JUIZ DE FORA. Prefeitura Municipal. Plano diretor de desenvolvimento urbano de Juiz de Fora. Juiz de Fora: FUNALFA, 1999.

MACHADO, P. J. O. (Org.) Diagnóstico físico-ambiental da bacia hidrográfica do Córrego São Pedro: um exercício acadêmico de gestão dos recursos hídricos. Ubá: Geographica, 2010.

MOOIJ, W. M.; TROLLE, D.; JEPPESEN, E.; ARHONDITSIS, G.; BELOLIPETSKY, P. V.; CHITAMWEBWA, D. B. R. et al. Challenges and opportunities for integrating lake ecosystem modeling approaches. Aquatic Ecology, v. 44, 2010. http://dx.doi.org/10.1007/s10452-010-9339-3

PACHECO, F. S.; SOARES, M. C. S.; ASSIREU, A. T.; CURTARELLI, M. P.; ROLAND, F.; ABRIL, G. et al. River inflow and retention time affecting spacial heterogeneity of chlorophyll and water-air $\mathrm{CO}_{2}$ fluxes in a tropical hydropower reservoir. Biogeosciences Discuss, v. 11, p. 8531-8568, 2014. http://dx.doi.org/10.5194/bgd-118531-2014

ROSMAN, P. C. C.; MASCARENHAS, F. C. B.; MIGUEZ, M. G.; CAMPOS, R. O.; EIGER, S. Métodos numéricos em recursos hídricos. 5. ed. Rio de Janeiro: ABRH, 2001.

ROSMAM, P. C. C. Subsídios para modelagem de sistemas estuarinos. In: ROSMAN, P. C. C.; MASCARENHAS, F. C. B.; MIGUEZ, M. G.; CAMPOS, R. O.; EIGER, S. Métodos numéricos em recursos hídricos. Rio de Janeiro: ABRH, 1999.

TUCCI, C. E. M. Hidrologia: ciência e aplicação. Porto Alegre: Ed. UFRGS, 2001.

WANG, S.; QIAN, X.; HAN, B.; LUO, L.; HAMILTON, D. P. Effects of local climate and hydrological conditions on the thermal regime of a reservoir at Tropic of Cancer, in southern China. Water Research, v. 46, n. 8, p. 2591-2604, 2012. http://dx.doi.org/10.1016/j.watres.2012.02.014 